\title{
Centrifuge simulation of heave behaviour of deep basement slabs in over-consolidated clay
}

\author{
D.Y.K. Chan \& S.P.G. Madabhushi \\ Department of Engineering \\ University of Cambridge, England
}

\begin{abstract}
High demand on land in major cities is driving construction of basement structures to create additional space. Long-term heave of base slabs is a pertinent problem in deep basement construction in overconsolidated clay strata, such as the London clay. Sub-structures must be designed to withstand soil pressures and displacements that evolve gradually for many years after construction is complete. This paper discusses an ongoing research project using centrifuge modelling to quantify the development of long-term heave by shortening the time-scale through dimensional similarity. The excavation process is simulated by draining of a heavy fluid (sodium polytungstate) and a model basement structure is instrumented to record the evolution of heave movements with time. This paper presents the preliminary results of a centrifuge test, which captured the magnitude of short-term differential and total heave deformation, the changes in support loads in horizontal props, and the evolution of pore pressures around the basement structure. Challenges encountered in this experimental technique and plans for further experimental work are discussed.
\end{abstract}

\section{INTRODUCTION}

Urbanisation is driving the demand for deep basements to be created within a dense built-environment to accommodate new public infrastructure such as underground railway stations and shopping mall cellars. The construction of a deep basement inevitably causes upward ground movements due to the permanent removal of soil overburden and these movements need to be predicted and controlled. In most geological strata, these ground movements are small and they occur within the timescale of the excavation, so they are accommodated during construction. However, in over-consolidated clay strata such as London clay, the soil permeability is so low that these upward movements continue for many years after structural completion. This process is known as long-term heave and the basement structure must be designed to withstand it, leading to much conservatism in design.

Some previous work has been carried out to quantify the effect of long-term heave using site data, notably a site on Horseferry Road, London where a basement was built in London clay and its heave movement was monitored for 21 years. Figure 1 shows that the evolution of heave movement with time at this site agrees with one-dimensional consolidation theory and this finding has served as a guideline for the designs of many deep basements in London clay. Although a few sites have published their moni-

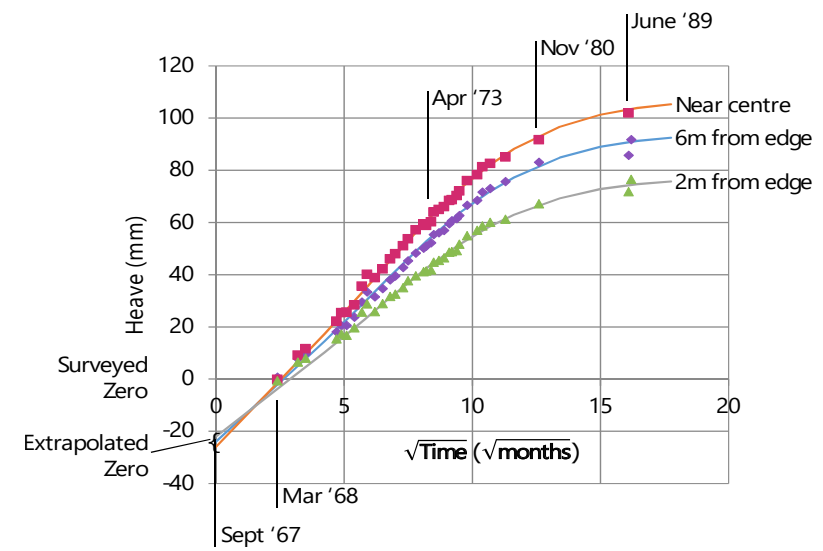

Figure 1: Monitoring data from Horseferry Road site. Continuous lines are 1D consolidation theory best-fit lines. (Courtesy of Sergio Solera of Mott MacDonald, Cambridge)

toring data, data availability remains scarce, and the complexity of live sites means that there is a need for experimental data to improve engineers' understanding of the underlying mechanisms of deformation. Previous researchers have performed geotechnical centrifuge simulations of basement heave in overconsolidated clay because this method can replicate full-scale soil and structure stresses, but these studies have generally focused on the effect of specific methods of heave mitigation (Ohishi et al. (2000); McNamara \& Taylor (2004)). There remains a need for an experimental study on the effect of the basement structure's stiffness on heave pressures and de- 
formations, which is the focus of the ongoing study described in this paper.

\section{MODEL DESIGN AND PREPARATION}

The research discussed in this paper is part of an ongoing series of experimental investigations to model the post-construction basal heave behaviour of a deep basement. Each test would involve a basement structure, complete with a base slab, underlain by a stratum of saturated, over-consolidated clay. The rest of this paper will discuss the initial centrifuge testing attempts of this problem.

\subsection{Design of basement model and excavation}

The experiment used a rectangular basement model made of aluminium alloy, whose dimensions were specified with the configurations of typical permanent basement structures in mind, except there was no tension embedment extending beneath formation level. Tension embedment was avoided as the main purpose of the testing was to promote upward heave of the base slab. Each wall and slab plate is $5 \mathrm{~mm}$ thick; at $100 \mathrm{~g}$ centrifugal acceleration this corresponds to a $1 \mathrm{~m}$-thick prototype reinforced concrete element.

The general arrangement of the model is shown in Figures $2 \& 3$. The plan area of the model is $150 \mathrm{~mm}$ $\times 300 \mathrm{~mm}$ (prototype $15 \mathrm{~m} \times 30 \mathrm{~m}$ ) and the buried depth is $150 \mathrm{~mm}$ (prototype $15 \mathrm{~m}$ ). Two props, each made from a $6 \mathrm{~mm}$ aluminium rod and a load cell, crossed from one long edge of the basement box to the other, at a level $25 \mathrm{~mm}$ above the soil surface. A $5.4 \mathrm{~kg}$ brass block was placed upon the short edges of the basement model to simulate the weight of an associated superstructure. The presence of a surcharge would encourage differential heave in the base slab, rather than a simple uplift of the whole basement. The joints of the basement box were bolted together with joint stiffeners.

Excavation was simulated by extracting a heavy fluid (sodium polytungstate solution) of the same den-

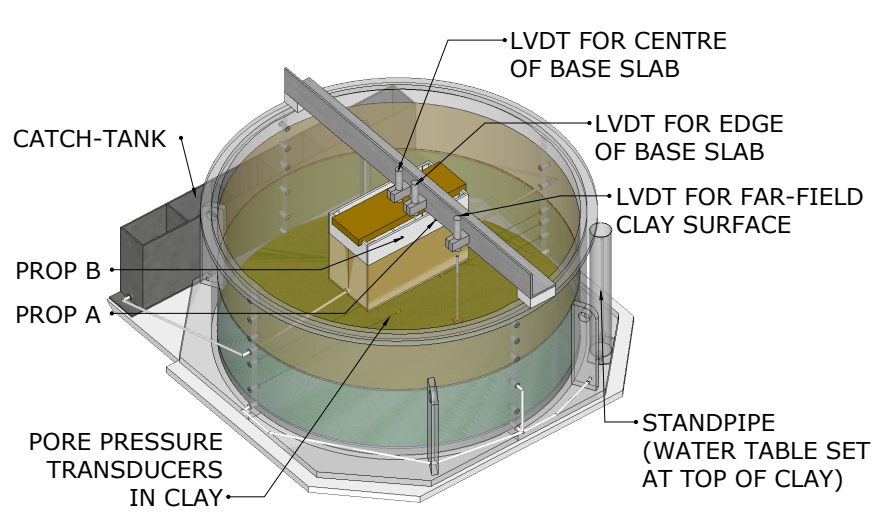

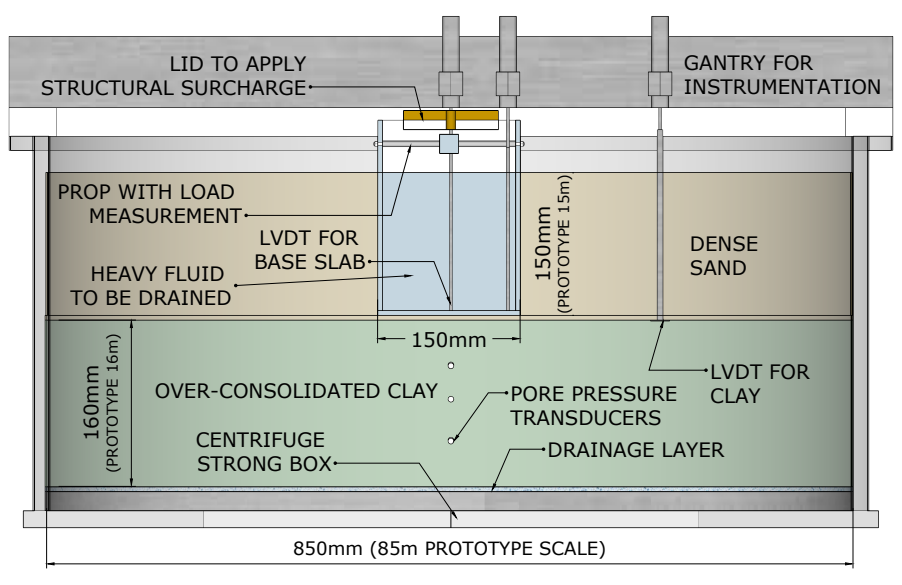

CROSS-SECTION

Figure 3: Cross-section of the centrifuge model, scale as shown

sity as the soil surrounding the basement. The basement box was buried in the soil and filled with heavy fluid before spin-up, so the vertical stress under the basement matches in-situ conditions before excavation, albeit the use of a liquid imposes $K_{0}=1$ on the soil surrounding the basement, as discussed by Lam (2010). At $100 g$, excavation was achieved by opening a set of valves to let the heavy fluid drain from the basement box to an external catch-tank under gravity (see Figures $2 \& 5$ ). The basement box was waterproofed with one layer of Plasti Dip rubber coating followed by two layers of Aquaseal tanking membrane. The use of a latex bag was not attempted because previous experiments had already shown that water-tightness between latex sheets and metal plumbing connections was unreliable under high fluid pressure.

\subsection{Model soil}

Long-term heave in over-consolidated clays is fundamentally caused by the swelling of the clay in response to the reduction in effective stress. This is characterised by the swelling index $\kappa$. Although Speswhite kaolin is commonly used in physical models of soil-structure interaction in clay, preliminary investigations on the one-dimensional compression and swelling behaviour of clay samples showed that the swelling index of kaolin is much lower than that of London clay. Therefore, an artificial clay mix comprising $90 \%$ Speswhite kaolin and $10 \%$ calcium bentonite $(\mathrm{K}+\mathrm{B}$ mix) was used to bring the swelling capacity of the clay in the centrifuge model to a level similar to that of London clay while preserving experimental repeatability. Table 1 presents the $\kappa$ values for different clays.

Table 1: Comparison of swelling indices of clays

\begin{tabular}{l|lll}
\hline Type of clay & Kaolin & London clay & $\mathrm{K}+\mathrm{B}$ mix \\
\hline$\kappa$ (Schmidt method) & 0.0485 & 0.0753 & 0.0707 \\
\hline
\end{tabular}

The centrifuge model involved two layers of soil: 
$160 \mathrm{~mm}$ of $\mathrm{K}+\mathrm{B}$ mix clay at the bottom, preconsolidated to a vertical effective stress of $800 \mathrm{kPa}$; and $150 \mathrm{~mm}$ of dry, dense Hostun sand (density $1595 \mathrm{~kg} / \mathrm{m}^{3}$ ) on top. This gives the clay an overconsolidation ratio of 2.1-3.4 in centrifuge flight. The formation level of the basement model was set at $5 \mathrm{~mm}$ above the sand-clay boundary. This arrangement allows the water table of the centrifuge model to be drawn down to the formation level so that there would not be any significant flotation and to provide adequate drainage at the bottom of the slab, but it also ensures that the basement structure was predominantly underlain by saturated clay.

After the centrifuge test, T-bar tests and shear vane tests were undertaken to measure the undrained shear strength of the clay in the centrifuge model. The Tbar's diameter was $8 \mathrm{~mm}$, its width was $40 \mathrm{~mm}$, and it was driven into the soil at a rate of $13 \mathrm{~mm} / \mathrm{s}$ (all model scale). All the strength measurements were taken from outside the footprint of the basement model. Figure 4 shows the results of these undrained shear strength tests, which reported values between $20-42 \mathrm{kPa}$. There is a general trend that undrained shear strength increased with depth, but there is also significant variation of strength for different samples at the same depth, which is presumed to be caused by uneven gain of moisture and loss of strength during the disassembly of the model from the centrifuge.

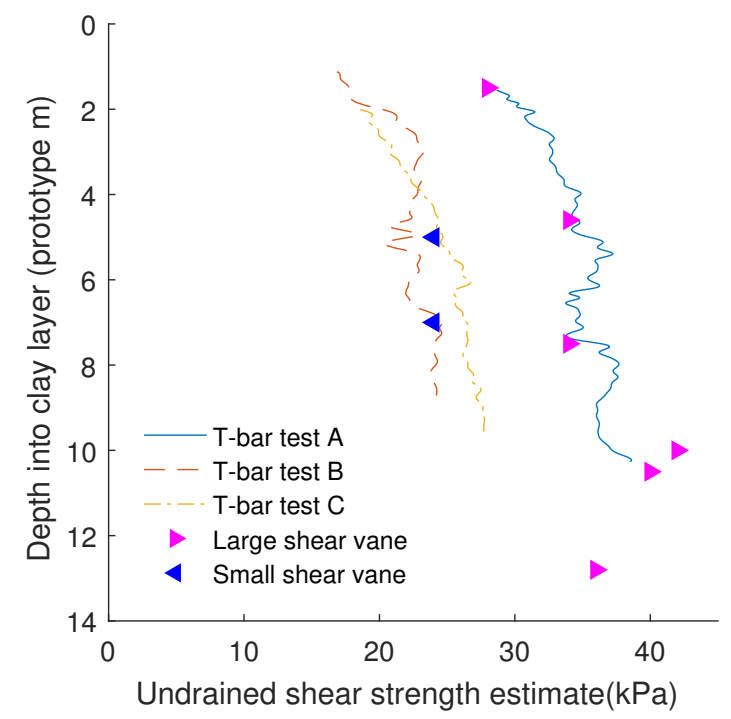

Figure 4: Undrained shear strength measurements in the $\mathrm{K}+\mathrm{B}$ clay layer (measured at $1 g$ )

\subsection{Model preparation and instrumentation}

To prepare the clay layer, bentonite powder was added to water in a vacuum mixer, followed by kaolin powder, to achieve a homogeneous slurry at $125 \%$ water content. The slurry was poured into a $850 \mathrm{~mm}$ diameter strong box, then put into an Enerpac consolidometer with double drainage, where the compressive load was doubled every 1-4 days until the vertical applied stress reached $400 \mathrm{kPa}$.
When the clay had consolidated sufficiently at $400 \mathrm{kPa}$ such that there was no significant reduction in volume in 24 hours, the vertical load was removed to put the clay into suction, then pore pressure transducers (PPTs) were installed through the side ports of the strong box. The consolidometer load was put back to $400 \mathrm{kPa}$ for a day, then increased to the desired pre-consolidation pressure of $800 \mathrm{kPa}$ and kept at the same load until there was negligible pore pressure change in a day. The load was then decreased from $800 \mathrm{kPa}$ to zero in $80 \mathrm{kPa}$ steps, keeping adequate water supply throughout the process, so that the PPTs would not experience absolute tension during model preparation, mitigating the chances of delamination or instrument damage. The strong box, the consolidation procedure, and the PPTs installation procedure used in this centrifuge model were the same as that described in Faustin (2017) except that this model required a larger load decrement during PPT installation. Overall, the clay slurry compressed from an initial height of $400 \mathrm{~mm}$ to a final height of $185 \mathrm{~mm}$ upon removal from the consolidometer.

The top $25 \mathrm{~mm}$ of the $\mathrm{K}+\mathrm{B}$ clay layer was scraped off to remove any surface contamination and reduce the thickness of the clay layer to the desired level. Then, a $5 \mathrm{~mm}$ layer of Hostun sand was laid upon the central part of the clay surface. The basement model was placed on top of this sand layer and connected via $1 / 4$ " BSP ports on the side of the tub to the external heavy fluid receiver tank. The automatic sand-pourer described in Madabhushi et al. (2006) then poured the rest of the $150 \mathrm{~mm}$ sand layer into the strong box. Figure 5 shows the complete centrifuge package assembled inside the Cambridge geotechnical beam centrifuge just before testing, showing the catch-tank in front, the top layer of sand and the instrumentation gantry on top, and the basement model in the middle.

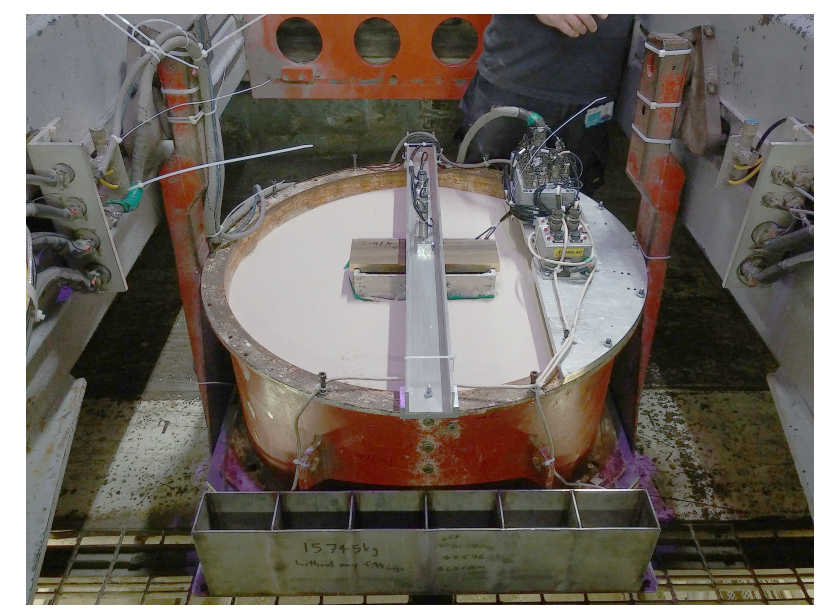

Figure 5: Photograph of centrifuge package assembled inside beam centrifuge

In addition to the aforementioned PPTs and load cells, the centrifuge model also included three linear variable differential transformers (LVDTs) to measure heave and settlement directly. The first LVDT measured displacement of the centre of the base slab; 
the second measured the side of the base slab; and the third measured the clay-sand boundary $150 \mathrm{~mm}$ (prototype $15 \mathrm{~m}$ ) away from the side of the basement using an extension foot which was laid down before sand-pouring. Additional pressure transducers were used to monitor the depth of heavy fluid in the basement box and the depth of water in the standpipe which set the water table. Figures $2 \& 3$ show the arrangement of instrumentation.

\section{PRELIMINARY RESULTS}
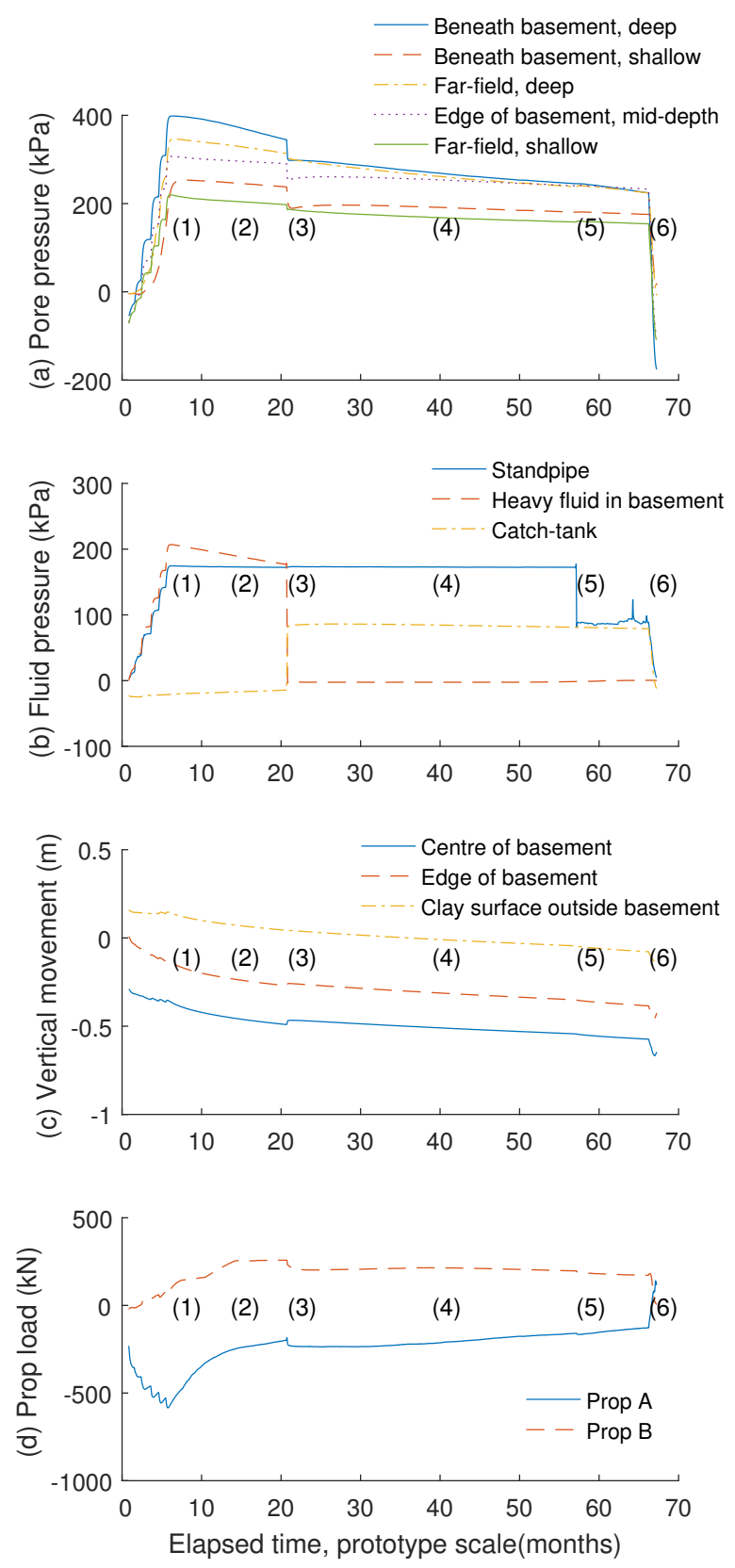

Figure 6: Graphs of instrument readings during centrifuge test, readings in prototype scale. (1) end of spin-up; (2) consolidation phase; (3) excavation; (4) post-excavation phase; (5) leak in water drainage; (6) spin-down

\subsection{Spin-up and re-consolidation}

In the main centrifuge flight, the initial plan was to allow five hours of centrifuge reconsolidation at $100 \mathrm{~g}$, but excavation was triggered prematurely at one hour after spin-up. This is because a cross-check of instrument readings had ascertained that there was a slow leak of heavy fluid from the basement box to the surrounding soil.

Figure 6 plots the variation of instrument readings throughout the centrifuge test, with axes in prototype scale using scale factors at $100 \mathrm{~g}$. The response of instruments during centrifuge spin-up and consolidation is plotted towards the left of Figure 6. The negative pore pressure that the clay maintained on removal from the consolidometer turned into a high positive pore pressure as the weight of the soil generated compression during spin-up, while imperfections in the installation of the props caused one of them to gain compression and the other to gain tension during spinup. Thereafter, the excess pore pressures dissipated slowly as the clay layer settled. Both props picked up compressive load, partly due to settlement of the basement box and partly due to the reduction in pressure inside the basement box from the slow leak.

\subsection{Excavation phase}

It is estimated that $15 \%$ of the heavy fluid had leaked from the basement box to the soil by the time excavation was triggered, bringing the fluid level in the basement box to $23 \mathrm{~mm}$ (prototype $2.3 \mathrm{~m}$ ) below the sand surface level. The remaining fluid took about $30 \mathrm{~s}$ (3.5 days in prototype scale) to drain from the basement box to the catch-tank. This caused undrained heave of the basement and there was an immediate response from the instrumentation. Figure 7(a) shows that both the middle and the edge of the base slab recorded significant undrained heave, whereas the farfield clay surface showed no discernible instantaneous movement in response to excavation.

Figure 8 shows that the base slab underwent both total heave and differential heave. The centre of the base slab heaved up by $21 \mathrm{~mm}(0.21 \mathrm{~mm}$ model scale) during the excavation and continued to heave afterwards relative to the far-field clay surface. The edge of the base slab heaved up by $11 \mathrm{~mm}(0.11 \mathrm{~mm}$ model scale) immediately and eventually stabilised at $13 \mathrm{~mm}$ heave.

Gasparre (2005) tabulated the undrained vertical stiffness $\left(E_{u}^{v}\right)$ for several London clay samples in triaxial extension. Her reported values clustered around $E_{u}^{v}=200 \mathrm{MPa}$. Taking this representative value of undrained stiffness, the removal of $175 \mathrm{kPa}$ of overburden from the excavation in this centrifuge test should lead to an undrained swelling strain of $0.09 \%$. If this strain was uniform over the 16 m-deep (model scale $160 \mathrm{~mm}$ ) clay stratum, the expected magnitude of heave would be $14 \mathrm{~mm}$. Allowing for differential 

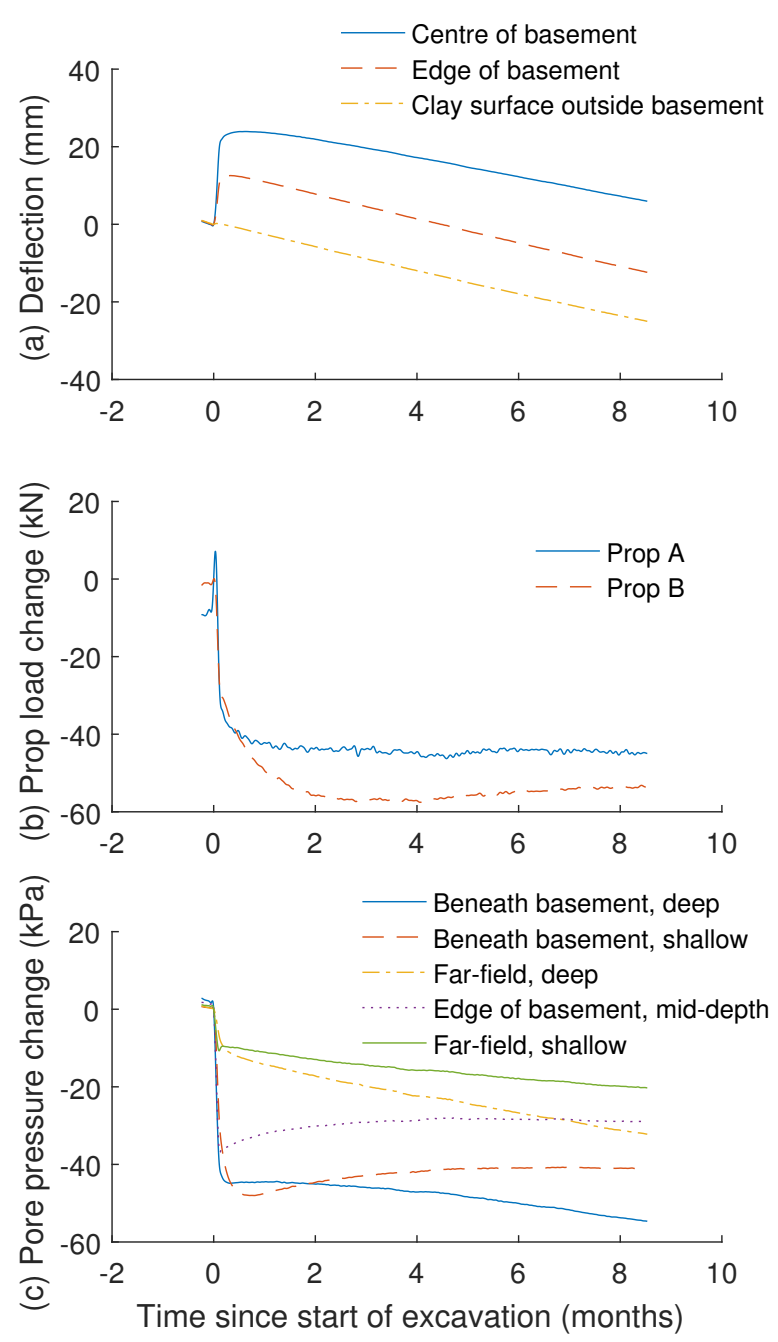

Figure 7: Change of instrument readings in response to excavation, relative to readings at the start of excavation; readings in prototype scale.

heave, the observed undrained heave of $21 \mathrm{~mm}$ at the centre $11 \mathrm{~mm}$ at the edge thus falls within the expected range. The magnitude of immediate heave also agrees with the observation that deep basement sites in London clay typically see a short-term heave displacement of $0.1 \%-0.2 \%$ of the excavation depth.

The compression in the prop loads decreased in the immediate response to excavation, which is perhaps counter-intuitive. This is because the slab-wall connections were deliberately made stiff, so the hogging deformation of the base slab was transferred into the walls as a prying movement. Figure 7(b) shows that the total drop in prop load was about $10 \mathrm{~N}$ in model scale, corresponding to a relief of $100 \mathrm{kN}$ of prototype prop load between the two props.

The excavation caused pore pressures below the basement to drop sharply, as expected. PPTs beneath and near the footprint of the basement recorded shortterm pressure drops of $38-49 \mathrm{kPa}$. The changes in pore pressures spread in all directions, with far-field, shallow-level PPTs also recording drops of about $10 \mathrm{kPa}$. Figure 7(c) shows that the pore pressures then recovered slightly as water was recharged into the

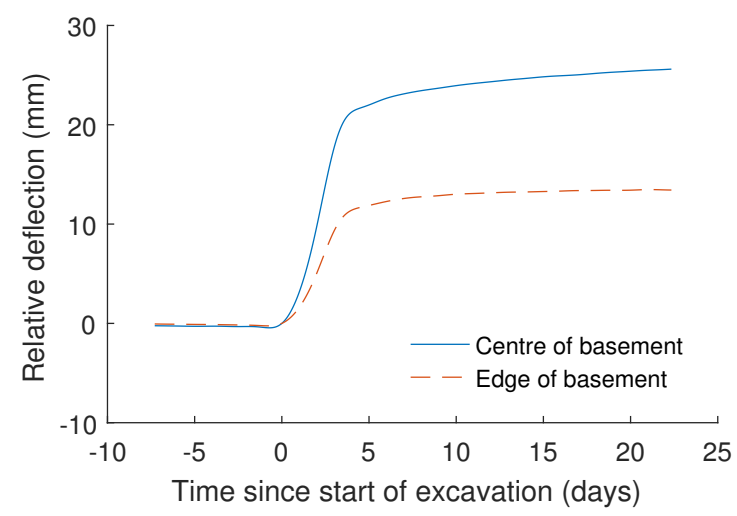

Figure 8: Short-term relative deflection of two positions of the base slab with respect to far-field clay surface, in prototype scale

clay layer, before continuing to decrease due to consolidation. Unfortunately, excavation was triggered before much consolidation had taken place due to the aforementioned technical difficulties, so the pore pressures remained well above hydrostatic throughout the centrifuge test.

\subsection{Post-excavation phase}

The short term response lasted about 8 months (2000 s in model scale) from the start of excavation. By this time, the recovery of pore pressures was complete. The centrifuge test continued for another two hours, during which the bulk of the clay layer continued to compress and excess pore pressures from spinup continued to dissipate. This is shown in Figure 9 which plots excess pore pressures relative to hydrostatic pressure and vertical movements of the three LVDT locations against $\sqrt{t}$, where time is measured from the end of spin-up, with units in prototype scale.

During the post-excavation phase, a slow downward trend of fluid pressure in the catch-tank raised concern. However, analysis of the data showed that this was caused by a drift of centrifuge speed. There was also some evaporation of water from the heavy fluid: the fluid recovered at the end of the centrifuge test was $6 \%$ denser than at the start. There was no sign of leakage of the heavy fluid out of the centrifuge package.

However, after 4.2 hours of centrifuge flight (corresponding to 4.8 years in prototype scale), a leak developed in the drainage fittings near the top of the clay, causing the water table to drop, and the test was stopped shortly afterwards.

\section{FUTURE WORK}

As discussed above, leakage was a significant challenge in this centrifuge model. The valves needed to hold shut at 5 bar pressure in the centrifuge and the first centrifuge flight was stopped soon after spin-up due to valve leakage; different valves were used in subsequent centrifuge flights. The basement box developed a slow-leak at $100 \mathrm{~g}$ despite its waterproof 

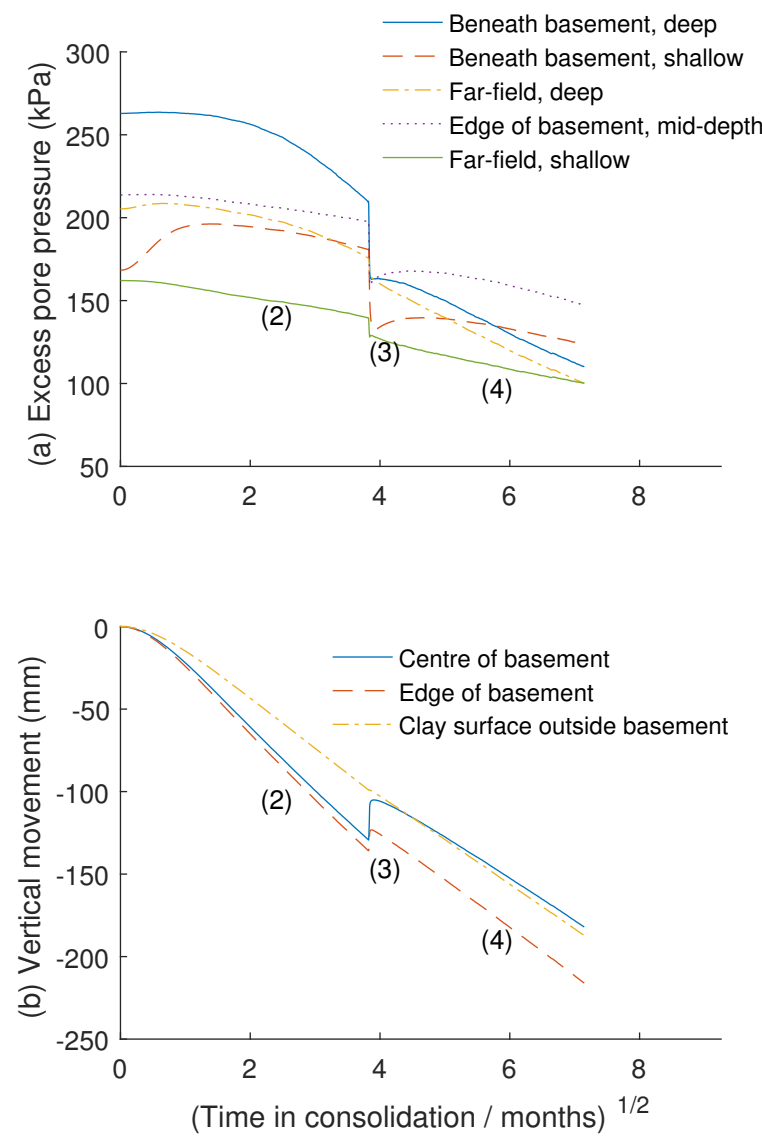

Figure 9: Graph of dissipation of excess pore pressures and changes in settlement against square-root of time in consolidation in prototype scale. (2) consolidation before excavation; (3) excavation; (4) post-excavation phase.

coating. Towards the end of the main centrifuge flight, a water supply connection providing top drainage to the clay layer also began to leak, causing the water table to drop. Fortunately, there was no leakage from the catch-tank which had fully welded joints, so there was no significant loss of mass from the centrifuge package which could upset the balance of the centrifuge. In future centrifuge tests, structural connections between metal components will be welded where watertightness is crucial.

The basement box used in this pilot test was specified with wall and slab stiffnesses commensurate to that of typical deep basement structures in London. Future tests will reduce the stiffness of the slab as the aim of this research project is to investigate the feasibility of using lighter designs of base slabs.

This pilot test only used two LVDTs to measure the heave movement of the base slab. The plan is to include further instrumentation such as strain gauges in future test to obtain more detailed measurements of the differential heave of the slab and the consequent bending in the base slabs and the basement walls. ment structures in over-consolidated clay.

- Instrumentation in the model was able to capture differential heave movements, changes in pore pressure, and changes in prop loads caused by undrained heave in response to excavation.

- Further work will be undertaken to improve equipment reliability, so that long-term heave can be reproduced and quantified in the model.

- Future investigations will aim to vary the stiffness of the model structure and also include additional instrumentation to shed light on the differential heave behaviour of the base slab.

\section{ACKNOWLEGEMENTS}

The authors would like to thank Dr. Yu Sheng Hsu, Hock Liong Liew and Sergio Solera of Mott MacDonald; and Dr. Wilson Kesse, Adam Locke and Corin Walford of Laing O'Rourke for their provision of past site data and information about current design practices.

This research project is supported by the EPSRC Centre for Doctoral Training in Future Infrastructure and Built Environment in the University of Cambridge.

\section{REFERENCES}

Faustin, N. E. (2017). Performance of circular shafts and ground behaviour during construction. PhD Thesis, Cambridge University.

Gasparre, A. (2005). Advanced laboratory characterisation of London Clay. PhD Thesis, Imperial College London.

Lam, S. Y. (2010). Ground movements due to excavation in clay: physical and analytical models. PhD Thesis, Cambridge University.

Madabhushi, S. P. G., N. E. Houghton, \& S. K. Haigh (2006). A new automatic sand pourer for model preparation at University of Cambridge. In Physical Modelling in Geotechnics.

McNamara, A. M. \& R. N. Taylor (2004). The influence of enhanced excavation base stiffness on prop loads and ground movements during basement construction. Structural Engineer 82(4), 30-36.

Ohishi, K., K. Azuma, M. Katagiri, \& K. Saitoh (2000). Deformation behaviour and heaving analysis of deep excavation. In Geotechnical Aspects of Underground Construction in Soft Ground, Tokyo.

Schmidt, B. (1966). Earth Pressures at Rest Related to Stress History. Canadian Geotechnical Journal 3(4), 239-242.

\section{CONCLUSIONS}

- This paper presented early attempts in centrifuge modelling of heave deformations of deep base- 